\title{
Review on Liquefaction Potential of Silts from CPT Data
}

\author{
M. Farooq Ahmed ${ }^{1}$, J. David Rogers ${ }^{2}$ and Joseph Cravens ${ }^{3}$ \\ 1. Department of Geological Sciences and Engineering, Missouri University of Science and Technology, Rolla 65401, MO, USA (On \\ leave from University of Engineering and Technology Lahore, Pakistan) \\ 2. Department of Geological Sciences and Engineering, Missouri University of Science and Technology, Rolla 65401, MO, USA \\ 3. Department of Civil, Architectural, and Environmental Engineering, Missouri University of Science and Technology, Rolla 65401, \\ MO, USA
}

\begin{abstract}
Soil liquefaction occurs when pore water pressure of low cohesion materials equals or exceeds the effective confining pressure. Sudden increases in pore water pressure may occur in response to dynamic loads, such as earthquake shaking, or shear strain engendered by sudden movement (static liquefaction). This study focused on the evaluation of the liquefaction potential of silty soils using CPT (cone penetration test) data. There is much less CPT data on the behavior of silts under dynamic loading, as compared to sandy soil mixtures. Robertson and Wride proposed a method of evaluating liquefaction evaluation for silt-sand mixtures using CPT data, when the soils contain less than $35 \%$ fines. Until more research is conducted, soils comprised of more than $35 \%$ fines cannot be reliably evaluated using CPT data alone. This is true for isolated silts or silt mixtures, which require laboratory testing to evaluate their liquefaction potential. Experience has shown that soils with $>35 \%$ silt can liquefy if drainage is retarded or severely restricted by bounding low permeability horizons, such as silty clays or clayey silts, which prevent dissipation of dynamically induced pore water pressures.
\end{abstract}

Key words: Liquefaction, pore pressure, dynamic loading, CPT, permeability.

\section{Introduction}

Soil liquefaction occurs in response to the sudden loss of shear strength in unconsolidated soils when pore water pressure equals or exceeds the effective confining stress. When the pore water pressure exceeds the confining stress, inter-particle friction is lost and the materials essentially behave as a fluid, devoid of any shear strength. As the excess pore water pressure is diminished by drainage and/or dilation, the material will gradually regain shear strength until it is of sufficient magnitude to cause the liquefied mass to solidify and cease moving. When granular soils are in a loose state, or silts in a soft state, and both are subjected to shearing stresses, the soil particles rearrange themselves to a more dense state if pore water is forced out. If the pore water is not allowed to dissipate, it will tend to increase in response to the shearing stress, leading to the transfer

Corresponding author: M. Farooq Ahmed, Ph.D., research fields: geotechnical and geological engineering. E-mail: mfanr5@mst.edu. of stresses from the soil skeleton to the pore water, causing a decrease in effective stress and reducing the mobilized shear strength of the soil. When the resistance of the soil becomes less than the driving shear stress, the soil can suddenly experience large deformations and liquefy $[1,2]$. "True liquefaction" refers to the flow of soil under a shear stress that exceeds the undrained, residual shear strength of a contractible soil [3].

Over the past five decades, it has become increasingly commonplace to evaluate saturated cohesionless soils for their liquefaction potential. Devastating effects of liquefaction came to the attention of geotechnical engineers in 1964 with the Great Alaska Earthquake and Niigata earthquake in Japan, followed by the Kobe earthquake in 1965 [4]. In the past 30 years, the liquefaction potential of sandy soils has been evaluated in depth and, as a consequence, a significant database exists regarding trigger thresholds for liquefaction of sands. During this same interim, the behavior of silty soil mixtures under 
dynamic loading has not been studied intensively and there is no definite criterion for evaluating the liquefaction potential of such soils. The influence of plasticity and void ratio has not been confirmed between constitutive models and actual field conditions [5]. Geo-professionals know that it can be a serious problem because the spectacular liquefaction of Turnagain Heights in Anchorage during the 1964 Great Alaska Earthquake occurred along a discontinuous horizon of silt lenses [6].

Robertson and Wride [1] developed a methodology for evaluating the liquefaction potential of sandy soils from the CPT (Cone Penetrometer Test) data. However, their evaluation is only acceptable if the sandy material has less than 35\% fines. Shuttle and Cunning [7] used the same approach evaluating soils for liquefaction potential based on the CPT, but they focused their attention on silt tailings rather than sands, and used a piezocone for their evaluations. This article seeks to build upon the work of Robertson and Wride [1] and Shuttle and Cunning [7] for evaluating liquefaction potential of silts using CPT data.

\section{Silt and Silt Mixtures}

For many years, silts and silty soils were considered non-liquefiable because most of the observed liquefaction failures occurred in sands. However, observations following the Haicheng (1975) and Tangshan (1976) earthquakes in China showed that many cohesive soils liquefied [8]. High plasticity silts and isolated soft clay horizons have been found to undergo cyclic mobility with small deformations, but do not tend to liquefy during large deformations. Non-plastic silts and silt mixtures with low PI (plasticity indices) have the potential to liquefy, as shown in the Alaska, Haicheng, and Tangshan earthquakes. Test data suggest that as the plasticity of a silt mixture increases, its resistance to liquefaction increases. For many years, it has been suggested that a range of PI values of clay fractions determines whether the liquefaction resistance increases or decreases $[5,9]$.

\section{Cyclic Resistance and Stress Ratio}

\subsection{Cyclic Resistance Ratio}

The resistance to cyclic loading determined from laboratory testing is influenced by the initial void ratio, effective confining stress, soil structure and cementation, cyclic shear stress, and the number of load cycles. Resistance to cyclic loading can be judged from the cyclic stress ratio, which controls liquefaction. This term is referred to as the CRR (cyclic resistance ratio). Testing of undisturbed samples tends to provide more reliable results than testing of more disturbed samples. However, it can be difficult or impracticable to obtain high-quality undisturbed samples for testing in saturated materials with low relative density and high void ratios. In such cases, procedures for estimating the CRR are employed rather than obtaining undisturbed samples for expensive laboratory tests. The most popular method for estimating the CRR comes from corrected SPT (standard penetration test) data [10]. Over the past few decades, the CPT has become increasingly popular because of its reliability, repeatability, and stream of continuous data [1]. SPT blow count $(\mathrm{N})$ correlations are useful for coarse-grained soils, primarily sands, but there is considerable uncertainty in making accurate correlations of fine-grained soils comprised of silts and clays [11].

\subsection{Cone Penetrometer Test}

The CPT (Cone Penetrometer Test) is an in-situ test used to evaluate soil profiles which retrieves data continuously with depth, and therefore, it is capable of detecting discrete stratigraphic lenses which are identified based on their physical behavior, not on mineralogy or fabric. The CPT is more capable of detecting nuances in the soil stratigraphy that are germane to soil behavior. During the test, a cone shaped head attached to the end of a rod and enclosed by an outer sleeve, is slowly pushed, vertically, into the ground. As the apparatus is advanced downward, 
the tip resistance and side friction is measured continuously. Generally, sands will produce low side friction and high tip resistance, while cohesive soils will produce high side friction and low tip resistance. The piezocone $(\mathrm{CPTu})$ is a cone penetrometer that is equipped with porous elements between the cone and the sleeve to allow pore water pressure measurements [12]. The CPT is often used in the first phase of a site investigation, followed by test borings to confirm the CPT data. It is also less prone to error due to the differences in equipment and technique, and is generally more reliable than the SPT $[11,13]$

Difficulties with oversize clasts and poor repeatability are often associated with the SPT; therefore, correlations have been proposed to estimate the CRR for clean sands and silty sands using the corrected penetration resistance measured by the CPT. The cone penetration resistance is corrected for the overburden stress, given as $q_{c l N}$, in order to estimate the CRR given below in Eq. (1) as

$$
q_{c 1 N}=\left(\frac{q_{c}}{P_{a 2}}\right) C_{Q}=\frac{q_{c 1}}{P_{a 2}}
$$

where, $q_{c}$ is the recorded cone tip penetration resistance; $C_{Q}=\left(P_{a} / \sigma_{v o}\right)^{n}$ is the correction for overburden stress; $n$ is typically equal to $0.5 ; P_{a}$ is the reference atmospheric pressure with the same units as $\sigma_{v o}^{\prime}$; and $P_{a 2}$ is the reference atmospheric pressure with the same units as $q_{c}$ [1]. The estimated CRR from the corrected cone penetration resistance has been shown to be reliable for clean sands, but insufficient research has been conducted to determine its applicability for silts or silt mixtures.

\subsection{Cyclic Stress Ratio}

The in-situ test methods require an estimate of the CSR (cyclic stress ratio). Seismic analyses for a specific site can be carried out to determine the CSR profile of a soil stratum. A method to estimate the CSR was developed by Seed and Idriss [14], which was based on the maximum surface acceleration $\left(a_{\max }\right)$ at a specific site. This approach is given below in Eq. (2) as

$$
C S R=\frac{\tau_{a v}}{\sigma_{v o}}=0.65\left(\frac{a_{\max }}{g}\right)\left(\frac{\sigma_{v o}}{\sigma^{\prime}{ }_{v o}}\right) r_{d}
$$

where, $\tau_{a v}$ is the average cyclic shear stress, $a_{\max }$ is the maximum acceleration at the ground surface, $g=9.81$ $\mathrm{m} / \mathrm{s}^{2}$ is the acceleration due to gravity, $\sigma_{v o}$ and $\sigma^{\prime}{ }_{v o}$ are the total and effective overburden stresses, respectively, and $r_{d}$ is the stress-reduction factor dependent on depth [1].

\section{Grain Size Characteristics}

There has been an increase in available field data for the CPT and the data have shown that the correlations to estimate the CRR are generally sound for clean sands. SPT or CPT penetration resistance is typically smaller in silts because of their potential compressibility and decreased permeability. One of the advantages of the SPT method has been its low cost and ability to recover physical samples for classification indices, such as fines content. As an increasing database is accumulated from CPT testing, the interpretive programs have become more robust and reliable. Grain size characteristics can now be estimated from CPT data in order to evaluate the liquefaction potential of silty mixtures. Robertson and Wride [15] recommended an average correction dependent on fines content, but not on penetration resistance. In order to determine a clean sand normalized penetration resistance, the following relationship can be employed, given in Eq. (3) as

$$
\left(q_{c 1 N}\right)_{c s}=K_{c} q_{c 1 N}
$$

where, $\left(q_{c l N}\right)_{c s}$ is the clean sand normalized penetration resistance, and $K_{c}$ is the correction factor, which is a function of the grain size of the soil [1]. The method for determining $K_{c}$ is described below in the following paragraphs.

Past research has shown that the CPT friction ratio (ratio of the sleeve friction to the cone tip resistance) tends to increase with fines content and soil plasticity. Robertson [16] developed a relationship between the normalized cone resistance and the normalized friction ratio, which can be used to determine the soil behavior type index $\left(I_{c}\right)$. This relationship is shown below in Eq. 
(4) as

$$
I_{c}=\left[(3.47-Q)^{2}+(\log F+1.22)^{2}\right]^{0.5}
$$

where, $Q=\left[\left(q_{c}-\sigma_{v o}\right) / P_{a 2}\right]\left(P_{a} / \sigma_{v o}{ }^{\prime}\right)^{n}$ is the normalized cone penetration resistance; $n$ is typically equal to 1.0 , $F=\left[f_{s} /\left(q_{c}-\sigma_{v o}\right)\right] 100$ is the normalized friction ratio, $f_{s}$ is the sleeve friction stress; $\sigma_{v o}$ and $\sigma^{\prime}{ }_{v o}$ are the total and effective overburden stresses, respectively, $P_{a}$ is the reference atmospheric pressure with the same units as $\sigma^{\prime}{ }_{v o}$, and, $P_{a 2}$ is the reference atmospheric pressure with the same units as $q_{c}$ and $\sigma_{v o}$ [15]. From the study of Robertson and Wride [15], the soil behavior type index increases with increasing fines content and plasticity. These ranges of indices are shown in Fig. 1. Based on the $I_{c}$, the correction factor, $K_{c}$, can then be determined as shown in Fig. 2. The relationship between the recommended correction factor, $K_{c}$, and the soil behavior type index, $I_{c}$, is presented as a broken or extrapolated line if $I_{c}$ is greater than 2.6, corresponding to an approximate fines content of $35 \%$. Soils containing an $I_{c}$ greater than 2.6 fall into the silts and silt mixtures range. Robertson and Wride [1] said "soils with $I_{c}>2.6$ are non-liquefiable".

\section{Liquefaction Potential of Silts from CPT}

By determining the $K_{c}$ from the $I_{c}$, the estimated equivalent clean sand normalized penetration resistance from the normalized penetration resistance of a silty sand mixture with less than $35 \%$ fines can now be estimated to determine the CRR, given below in Eqs. (5) and (6) as

$$
\begin{gathered}
\text { if } 50 \leq\left(q_{c 1 N}\right)_{c s}<160, \\
C R R=93\left[\frac{\left(q_{c 1 N}\right)_{c s}}{1000}\right]^{3}+0.08
\end{gathered}
$$

if $\left(q_{c 1 N}\right)_{c s}<50, C R R=0.833\left[\frac{\left(q_{c 1 N}\right)_{c s}}{1000}\right]^{3}+0.05$

Hence, the liquefaction potential of silty sand mixtures could be estimated by determining the factor of safety against liquefaction and dividing by the CRR estimated from the cone penetration test by the CSR, based on the maximum ground surface acceleration given in Eq. (7), below as

$$
F S_{\text {liq }}=\frac{C R R}{C S R}
$$

The CPT methodology is an alternative to the SPT or shear wave velocity $\left(V_{s}\right)$ in-situ methods. However, using more than one method is useful in comparing evaluations of liquefaction potential of different soils [1].

\section{Liquefaction Potential of Silts from Piezocone}

\subsection{New Approach to Assess Liquefaction Potential of Silts}

Following the studies of Robertson and Wride [1], which evaluated liquefaction potential without pore water pressure measurements from the CPT, Shuttle and Cunning [7] studied the liquefaction potential of silts using piezocone data. Silt tailings (slimes) were studied in their research. The current liquefaction evaluations focus on clean sands with less than 5\% fines, with the highest fines content considered for correlations being 35\%. However, the Merriespruit Tailings Dam failure in South Africa demonstrated that the tailings with a higher silt-sized fraction were capable of liquefying [17].

The behavior of silts resembles both sands and clays. Loose isolated silts, similar to sands, are very difficult and expensive to obtain undisturbed samples. These factors have led to the electronic piezocone penetration test (CPTu) becoming increasingly used to assess mine and tailings. Forcing the CPT through silty soil mixtures produces excessive pore water pressure, unlike the evaluation in sands where drainage is allowed. The density of silt affects its behavior, so the evaluation of CPT data using total stress methods generally yield undrained shear strength values, $s_{u}$, leaving questions about what these strengths mean in terms of liquefaction potential.

Shuttle and Cunning [7] focused their study on the Rose Creek Tailings Impoundment located at the Anvil Range Mining Complex near Faro, in the Yukon Territory of Canada. Between 1969 and 1992, tailings from an adjacent mining complex were deposited in the Rose Creek Tailings Impoundment. The tailings were deposited hydraulically over the life of the mine's 




Fig. 1 Variation of CPT $I_{c}$ with FC (\%) by Robertson 1990 (after Robertson and Wride [15]).

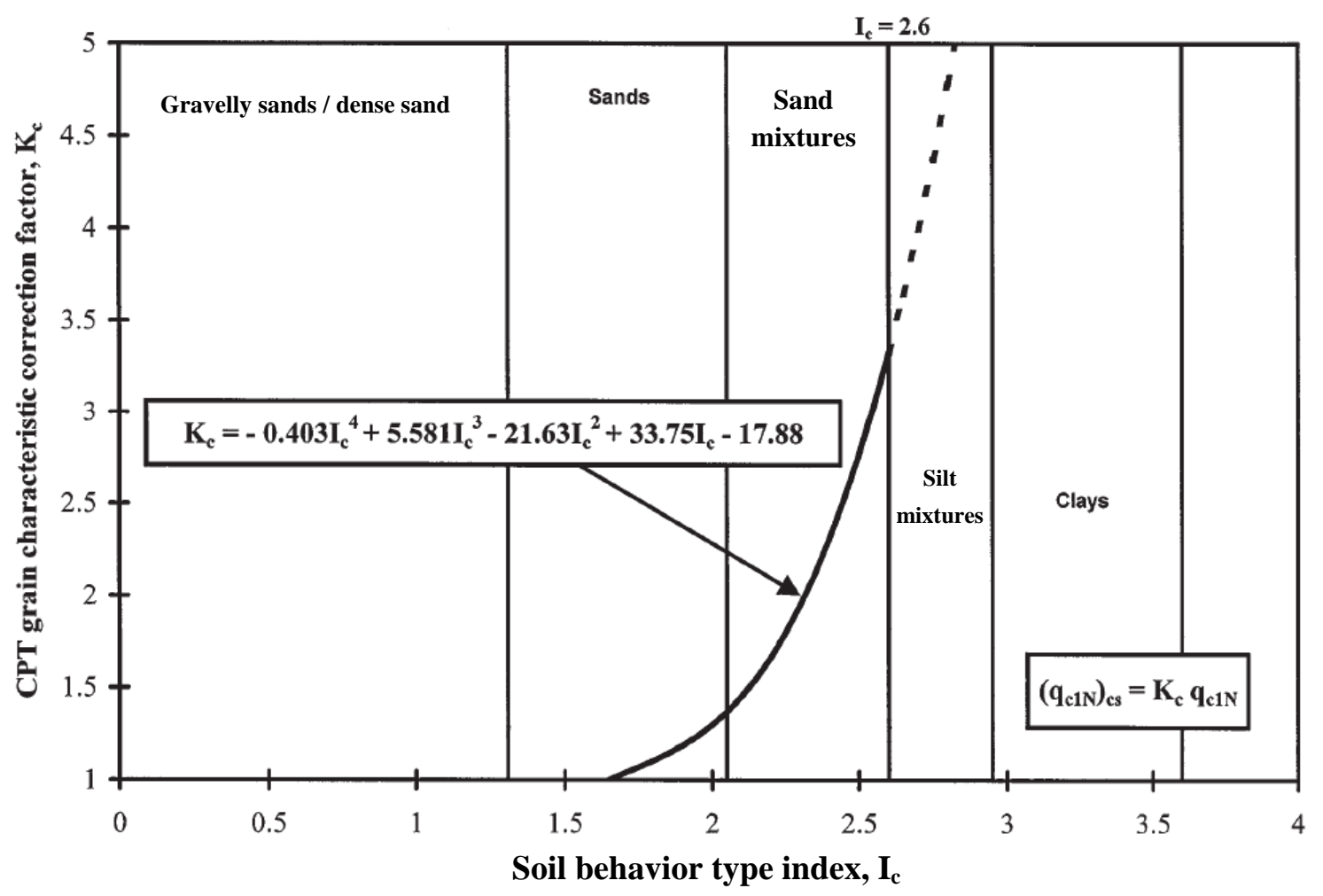

Fig. 2 Grain characteristic correction $\left(K_{c}\right)$ to obtain $\left(q_{c 1 N}\right)_{c s}$ (after Robertson and Wride [15]).

operation, producing separation and a range of gradations. The concern was whether the silt tailings had the potential to liquefy and flow over the retention dams because of the elevation of the tailings. 


\subsection{In-Situ Testing}

The CPT data included the tip resistance $\left(q_{c}\right)$, skin friction $\left(f_{s}\right)$, pore water pressure $\left(u_{c}\right)$, friction ratio $(F)$, excess pore water pressure ratio $\left(B_{q}\right)$, and the normalized cone penetration resistance $(Q)$. The pore water pressure, cone tip resistance, and overburden stress is used to determine $B_{q}$, given below in Eq. (8) as

$$
B_{q}=\frac{u_{c}-u_{o}}{q_{c}-\sigma_{v o}}
$$

Where, $u_{c}$ is the measured pore water pressure, $u_{o}$ is the hydrostatic pore water pressure, $q_{c}$ is the measured cone tip resistance, and $\sigma_{v o}$ is the total overburden stress. The silt tailings were at depths between $4 \mathrm{~m}$ and $12 \mathrm{~m}$, below the surface as identified by the $B_{q}$ values. Monitoring wells were installed to investigate the water quality in the impoundment which further confirmed the measured $B_{q}$ values. The soil type index $\left(I_{c}\right)$ was produced from the $Q, B_{q}$, and $F$ values. The high $B_{q}$ values indicated that the silt classified on a soil behavior type basis as "soft clay" to "organic soil" [7].

The CPT used at the site recorded shear wave velocities as well as pore water pressure measurements (CPTu). The shear modulus was high for the soft soil, ranging from $55 \mathrm{MPa}$ at the top of the tailings column to $130 \mathrm{MPa}$ at the bottom. Test borings were also performed at the site to confirm the CPT interpretations, and the water contents were determined for each sample obtained. These were converted to void ratios (e) and the average was $e=1.1$. All of the samples obtained were disturbed, which could have affected the water contents. Also, these estimates of void ratio were approximate, which is another reason why the CPT was performed. After the investigation, the silts were considered non-plastic, with about $66 \%$ of the soil being silt-sized particles and the remainder consisting of fine sand [7].

\subsection{Laboratory Testing}

Four iso-tropically consolidated triaxial tests of the mine tailings were conducted to determine the critical state parameters $\left(\Gamma, \lambda_{10}, M_{t c}\right)$. Two tests were undrained and the other pair were drained. Reconstituted samples were prepared by the moist tamping method, so the samples could reach a defined critical state from the strain limits in a triaxial test. Saturation of the samples included carbon dioxide, de-aired water, and back pressure saturation. After the carbon dioxide and de-aired water treatment, the samples were considered to be fully saturated with a back pressure saturation value $(B)$ greater than $96 \%$. The confining stress during the test was maintained at $20 \mathrm{kPa}$, and the samples were consolidated to the desired stress, and volume changes were recorded in order to determine the changing void ratio during the test. The maximum and minimum void ratios were also determined for the silt tailings and were found to be 2.017 and 0.837 , respectively [7].

\subsection{Evaluation of Test Results}

To determine the CSL (critical state line), the void ratio of the samples was needed. After shearing of the sample reached critical state, the final void ratio was determined using the total sample freezing method, which allowed for an accurate final void ratio determination. The CSL was estimated from the tests by a semi-logarithmic trend line through the plots of void ratio versus mean effective stress, as well as the mean effective stress versus the deviator stress. The CSL was well defined on the plots; the moist tamping method did not appear to affect the critical state void ratios. Based on the results, the critical state parameters were determined to be: $\Gamma=1.076, \lambda_{10}=$ 0.159 and $M_{t c}=1.25$ [7].

The silt samples were not able to be tested at their in-situ void ratio, which was obtained from the in-situ water contents. Contraction of the samples occurred during the saturation process and during consolidation; therefore, testing in shear started from void ratios in the range $0.7<e<0.8$ and were compared with the in-situ void ratios in the range $0.9<e<1.3$. The silt's state, characterized by the state parameter $\Psi$, was about +0.3 , determined from the in-situ critical void ratio in the range of 0.76 and 0.71 . Shuttle and 
Cunning [7] said "such very positive states are normally catastrophically liquefiable under minor static triggering, and they are certainly exceedingly liquefiable in any credible design earthquake scenario".

\subsection{Comparison of Methodology}

Based on the liquefaction potential from CPT methodology suggested by Robertson and Wride [1], the soil was assumed to be non-liquefiable for $I_{c}$ values greater than 2.6. The CPTu data obtained from the Rose Creek Tailings Impoundment exhibited $I_{c}$ values greater than 2.6, so the Robertson and Wride [1] methodology would consider the soil to have no liquefaction potential. But, the soil is highly liquefiable by introducing pore water pressure to the methodology. More confirmation of the liquefaction potential can be gleaned from the high $B_{q}$ values [7], which were consistent with the complete loss of shear strength from shearing around the tip of the cone. Shuttle and Cunning [7] further confirmed their findings of the liquefaction potential of the silt tailings from numerical modeling.

\section{Conclusions and Recommendations}

The liquefaction potential evaluation procedure of Robertson and Wride [1] based on CPT data has been accepted for sandy soils with less than 35\% fines and exhibiting a soil type index less than 2.6. The study performed by Shuttle and Cunning [7] using CPTu data has shown that silt tailings with $66 \%$ silt particles and soil type indices greater than 2.6 also have the potential to liquefy. Although the Shuttle and Cunning [7] study did not include laboratory testing; the liquefaction potential of silt-size mine tailings has been observed in many tailings containment failures.

Presently, it appears that there has been insufficient research conducted to confirm the liquefaction potential of silts from CPT data alone. For silt-sand mixtures, the Robertson and Wride [1] liquefaction CPT-based evaluation is one of the only reliable methods for soils containing less than 35\% fines, and is often used by geotechnical engineers. A study on silty sand by Moayed et al. [18] is one of the references cited by Robertson and Wride [1] supporting their CPT-based methodology.

Until more research is conducted, soils profiled by CPT with more than $35 \%$ fines, whether consisting of isolated silts or silt mixtures, will require additional laboratory testing to evaluate their liquefaction potential. Future research for the evaluation of the liquefaction potential of silts using CPT soundings should assess soil type indices greater than 2.6, and the liquefaction potential of silty soils. Boulanger and Idriss [19, 20] studied the liquefaction potential and cyclic softening of silts and clays and Robertson [21] provided an update for the use of CPT performance in earthquake design. These references include, but are not limited to, materials that should be incorporated into the future research for the evaluation of liquefaction potential of silts using CPT data.

\section{References}

[1] Robertson, P. K., and Wride, C. E. 1998. "Evaluating Cyclic Liquefaction Potential Using the Cone Penetration Test." Canadian Geotechnical Journal 35 (1): 442-59.

[2] Rauch, A. F. 1997. "EPOLLS: An Empirical Method for Predicting Surface Displacements Due to Liquefaction-Induced Lateral Spreading in Earthquakes." Ph.D. thesis, Virginia Polytechnic Institute and State University.

[3] Castro, G. 1987. "On the Behavior of Soils during Earthquakes-Liquefaction." In Soil Dynamics and Liquefaction, edited by Cakmak, Amsterdam: Elsevier Science Pub..

[4] Kramer, S. L. 1996. Geotechnical Earthquake Engineering. Upper Saddle River, NJ: Prentice Hall.

[5] Guo, T., and Prakash, S. 1999. "Liquefaction of Silts and Silt-Clay Mixtures." Journal of Geotechnical and Geo-environmental Engineering 125 (9): 706-10.

[6] Seed, H. B., and Wilson, S. D. 1967. "The Turnagain Heights Landslide, Anchorage, Alaska." Journal of the Soil Mechanics and Foundations Division 93 (July): 325-53.

[7] Shuttle, D. A., and Cunning, J. 2007. "Liquefaction Potential of Silts from CPTu." Canadian Geotechnical Journal 44 (1): 1-19. 
[8] Prakash, S., and Puri, V. K. 2006. Liquefaction of Fine Grained Soils. San Francisco, CA: 8 NCEE.

[9] Seed, H. B., and DeAlba, P. 1986. "Use of SPT and CPT Tests for Evaluating the Liquefactions Resistance of Sands." In Use of on Situ Tests in Geotechnical Engineering, edited by Clemence, S. P. ASCE Geotechnical Special Publication No. 6: 281-301.

[10] Skempton, A. W. 1986. "Standard Penetration Test Procedures and the Effects in Sands of Overburden Pressure, Relative Density, Particle Size, Aging and Overconsolidation." Geotechnique 36 (3): 425-47.

[11] Rogers, J. D. 2006. "Subsurface Exploration Using the Standard Penetration Test (SPT) and Cone Penetration Test (CPT)." Environmental \& Engineering Geoscience 12 (2): 161-79.

[12] Budhu, M. 2007. Soil Mechanics and Foundations. 2nd ed. Hoboken, NJ: John Wiley \& Sons.

[13] Coduto, P. D. 1999. Geotechnical Engineering Principles and Practices, 2nd ed.. Prentice Hall, Upper Saddle River, NJ.

[14] Seed, H. B., and Idriss, I. M. 1971. "Simplified Procedure for Evaluating Soil Liquefaction Potential." Journal of the Soil Mechanics and Foundations Division, ASCE 97 (9): 1249-73.

[15] Robertson, P. K., and Wride, C. E. 1995. "Liquefaction of Sands and Its Evaluation: Keynote Lecture. IS Tokyo '95.”
In Proceedings of the 1st International Conference on Earthquake Geotechnical Engineering, Tokyo, Japan, AA Balkema, Amsterdam.

[16] Robertson, P. K. 1990. "Soil Classification Using the Cone Penetration Test." Canadian Geotechnical Journal 27 (1): 151-8.

[17] Fourie, A. B., Blight, G. E., and Papageorgiou, G. 2001. "Static Liquefaction as a Possible Explanation for the Merriespruit Tailings Dam Failure." Canadian Geotechnical Journal 38 (1): 707-19.

[18] Moayed, R. Z., Naeini, S. A., and Baziar, M. H. 2002. "Evaluation of Liquefaction Potential of Loose Silty Sand Based on CPT Results." In Proc. of the Canadian Geotechnical Society Conference, 95-100.

[19] Boulanger, R. W., and Idriss, I. M. 2004. Evaluating the Potential for Liquefaction or Cyclic Failure of Silts and Clays. Report No. UCD/CGM-04/01, University of California, Davis, CA.

[20] Boulanger, R. W., and Idriss, I. M. 2007. "Evaluation of Cyclic Softening in Silts and Clays." Journal of Geotechnical and Geo-environmental Engineering, ASCE 133 (1): 641-52.

[21] Robertson, P. K. 2009. "Performance Based Earthquake Design Using the CPT." In Case History to Practice, edited by Kokusho, T., Tsukamoto, Y., and Yoshimine, M. CRC Press. 